\title{
Exploring the Negative Transfer on English Learning
}

\author{
Xiaoru Wang \\ English Department, XianYang Normal University \\ XianYang 712000, China \\ E-mail: wxrdgq@sina.com
}

\begin{abstract}
According to the language transfer theory, it is assumed that the learner's mother tongue (MT) will positively or negatively affect his learning a foreign language in second language acquisition (SLA). When there are differences between his (MT) and target language (TL), the learner's mother tongue and target language are similar, the native language will actively aid foreign language in learning that is in case of similarities between the native language and target language, the transfer functions positively, while in case of differences, it functions negatively.

The mother negative language transfer in acquiring a foreign language is seemingly inevitable. Since the differences between the learners' MT and TL will interfere with the target language learning. On the basis of the theories of contrastive analysis, transfer analysis and translation theories, this paper is an attempt to find out the phenomena of mother language's negative transfer in English learning by means of Chinese-English translation, with the purpose of showing how the Chinese learners of English are negatively influenced by their mother tongue knowledge in learning English. The author will collect the data of Chinese-English translation from the fresh men and analyze the reasons. At last, the author will make suggestions for teachers and learners according to the mistakes the subjects made.
\end{abstract}

Keywords: Mother tongue, Language transfer, Negative transfer

\section{Introduction}

Language transfer has been a central issue in applied linguistics, second language acquisition and language learning (Odlin 11). Since its appearance in the 1960s, with the change of the major theory in second language acquisition, the theory of language transfer has also experienced ups and downs. In 1950s, transfer was considered the most important factor that contributed to errors. In the 1960s, the study of transfer waned as linguistic revolution led by Chomsky severely shook the psychological base for behaviorist learning theory, and learners' errors were not seen as evidence of language transfer but rather of the creative construction process. In 1980s, however, the study of transfer renewed its development and more balanced perspective of transfer researches have emerged when the study of L2 (second language) acquisition and intercultural communication reached a new stage.

Transfer, derived from the Latin word transferee, means to carry, to bear or to print, impress or otherwise copy (as a drawing or engraved design) from one surface to another. So to speak, when we say technology transfer, we mean the transfer or carry-over of technology from one owner to another. Transfer can also mean the carry-over or generalization of learned responses from one type of situation to another, especially the application in one field of study or effort of knowledge, skill, power, or ability acquired in another. By linguistic transfer, we mean what the learners carry over or generalize in their knowledge about their native language (NL) to help them learn to use a target language (TL).

The transfer occurs at the level of lexis, sentential and discourse. This paper only refers to the sentential level.

\section{Study}

These materials of study come from subjects' Chinese-English translations from Chinese and Math Department, Xian Yang Normal University. Since all of them have acquired the basic knowledge about English as required by the National Syllabus in their school years, they are proficient and accurate in translating the text. The study consists of two steps. The first one is pilot study and the formal study comes the second. In the pilot study, the translation materials are given to 10 students in Math Department and 13 in Chinese Department. Their translations are observed from five aspects including subject omission, the choice of pronoun-subject or non- pronoun-subject, redundancy, time expression and the location of negative object. In the formal study, the sentences required to translate from the aspect of subject omission have been changed into run-on sentences for few errors made by the students in translating them. 
The samples are 52 finished pieces of translations from 81 students. We will use them as the language materials of this study. The author has numbered all of them.

\section{Insert Table 2.1 Here}

The subjects have mastered the subject-omission (1-3 in Pilot Study) very well and done well in translation. The Choice of Pronoun-subject or Nonporous-subject (4-6 in both Pilot and Formal Study) is very obvious mistaken by the subjects both in pilot and formal study. When it refers to Redundancy (7-9 in both Pilot and Formal Study), more than half of them have made such improper expressions. They must have mastered the Run-on Sentences (1-3 in Formal Study) well and did little wrong. From the table 2.1, it comes to the conclusion that they lack knowledge about Time Expression (10-12 in both Pilot and Formal Study). Generally speaking they are negatively transferred by mother tongue language.

\section{The Data Analysis}

"Chinese belongs to the Sino-Tibetan language which has the system of ideogram. Sino-Tibetan is one of the world's largest language families in terms of numbers of speakers and includes the language most widely spoken as a native language, namely Mandarin Chinese" (Aronoff and Jaine 26).

Chinese is a topic-prominent language, and the thought and the order of words naturally mingle together. In a sentence, first come the topic and then the comments. English belongs to the Indo-European language which has the system of speech and written. The Indo-European Family of languages of Europe are considered to have a common source, a hypothetical language spoken several thousand years ago. To find an ancestor common to both French and German or both French and Prussian, one has to go much further back in time" (Stuart 145). English is a subject-prominent language. The English sentence obeys the syntax structure strictly, so the order of the words is restrained by many rules, and most of the meaning is implied in the sentence. So there are great differences between the two languages in sound, syntax, semantics, and so on. According to the Chinese learners, the rules of the mother tongue are ineradicable which they usually unconsciously apply in English learning. Because of the great distinction between Chinese and English, some negative transfers are inevitable in translation.

\subsection{Subject Omission}

The subject in English sentence cannot be missed. And the predicate is taken as the centre; the subject is mutually restrained by the predicate. However, the subject in Chinese sentence can be missed. So we can miss the subject when conveying something and there exist a lot of zero subjects in Chinese sentence. Therefore, when learners try to translate Chinese into English, the negative transfer from mother tongue will influence the interpretation of subject. In the pilot study, three sentences were used.

The author thought there would be many mistakes made by the subjects; in contrast, the data has showed the other side. NO.1 is $0 \%$, NO.2 is 7\% and NO.3 is $0 \%$. So the students have already got abundant knowledge about the distinction between the subjects of Chinese and English.

\subsection{The Choice of Pronoun-subject or Non-pronoun-subject}

Chinese people always hold the idea that human being and nature are mingled together, so Chinese people intend to make themselves as the start to narrate object things and are used to taking the pronoun as the subject. However, in the western philosophy, object is emphasized and it is believed that human being and nature are separated. So western people intend to express things from an object view and are used to taking non-pronoun such as things or abstract concept as the subject. The choice of pronoun-subject or non-pronoun-subject between Chinese and English will lead to negative transfer of mother tongue, which will make the translation of subject an improper one.

1). A. I suddenly think of this thing is not so easy.

2). A. You only study it carefully; you will find where the problem is.

3). A. He does not obey the traffic rule; the car has run into trouble.

In the pilot study, most subjects have taken the pronoun as the subject. NO.4 is $100 \%$, NO.5 is $100 \%$ and NO.6 is $71 \%$. Moreover, in the formal study, all the subjects have taken the pronoun as the subject. NO.4 is $100 \%$, NO.5 is $100 \%$ and NO.6 is $100 \%$. It proves that the Chinese students are easily influenced by the pronoun-subject sentence. They translate 'wo' into the English sentence mechanically according to the Chinese type sentence. Although there is no grammar mistake, it is somewhat Chinglish rather than idiomatic expression in English. So the sentences should be like this:

1). B. It occurs to me that this affair is much more difficult.

2). B. Careful study of them will show you where the problem is.

3). B. His failure to observe the traffic regulations bring an accident to the car.

\subsection{Redundancy}

From the view of informative theory, redundancy is the necessary part in language communication. During the process 
of delivering information, there is always some interruption of noises. So in order to keep the accuracy it is important for the message sender to add some proper redundancy. But both too much and too little of it will definitely lessen the efficiency or make the sentence look dull. Chinese and English belong to two different symbol systems, so there are many differences in the ways of expression. The redundancy coming from mother tongue will affect the Chinese-English translation with many clingfish. There are many habitual collocations in Chinese. If they are literally interpreted into English, the excessive redundancy would appear, and it would not be in accordance with simple and convenient style of English. Take noun for example, there are a lot of category words used to indicate category and property. Although they do not have practical meaning, they are necessary in Chinese expression. When they are translated into English, most of them must be missed.

4). A. The state leaders pay special attention to the development in the sphere of the culture.

5). A. All the universities and colleges must solve the problem of controlling the inflation in the restaurant.

6). A. The improvement of the teaching quality remains the important foundation for the developments of Xian Yang normal university.

The interpretations should be:

4). B. The state leaders pay special attention to the developments in the culture.

5). B. All the universities and colleges must control the inflation in the restaurant.

6). B. The improvement in teaching remains the foundation for the developments of Xian yang Normal University.

\subsection{Run-on Sentences}

There is distinction between the sentences of Chinese and English. In English there exist many conjunctions, preposition, relative pronoun, three non-predicate forms and sixteen tenses, which makes the English sentence very complex. However, there is no participle in Chinese. Words like conjunction, preposition and relative pronoun are not rich, and verbs are exceptional.

If you put two independent clauses together without proper punctuation, you have made an error called a run-on sentence, which can also be called a fused sentence. Run-on sentences are generally created when you attempt to coordinate sentences but do not use the correct punctuation.

Incorrect use of run-on sentences is the common problem among subjects due to the influence of the Chinese language. Run-on sentences are sentences that two main clauses are con-nected without a connecting word or punctuation. The data shows that run-on sentences are affected by Chinese sentences structure. However, such a sentence structure is allowed in Chinese while forbidden in English.

For example, some students translate these sentences like this or similar ones:

7). Unfortunately, it is power failure in the school, we cannot surf the internet.

8). It is not rainy today; we can go out to play.

9). The story is end here, nobody want to go.

In Chinese, although there is no conjunction 'because', we can still understand the former part of the sentence is the cause of the later. While in English, without a conjunction in the sentence is prohibited. The second and third sentences should be the similar. $30.8 \%$ of the subjects have made this kind of mistake like the first one, $51.9 \%$ and $11.5 \%$ for the second and third. The correct version should be:

7). Unfortunately, it is power failure in the school, so we cannot surf the internet.

8). It is not rainy today, so we can go out to play.

9). The story is end here, but nobody wants to go.

\subsection{The Location of Negative Object}

In Chinese, the negative words like ' $b u$ ', 'fei', 'mei (you)' are all directly put before the object words. However, in English, although 'not' is put together with the predicate verb to deny some other parts of the sentence. So it is not directly put before the negative object words. Therefore, it comes the problem of locating negative object. The meaning of the whole sentence will be misled or mistaken by making an incorrect location of the negative object. There are also some negative meanings in the complex sentence. The negative word in Chinese sentence is naturally put before the object word, while the negative word in corresponding English sentence can only be put before the verb. Chinese students cannot get into the habit, which do not obey the normal order of Chinese words and they frequently make mistakes.

Many subjects have made such mistakes with the influences of the mother tongue, and they translate above sentence like this: 
10). A. I think all he has done is not for money.

11). A. Mother believes that father has not told the truth.

12). A. Tom thought some employees have not done their best.

They just locate the negative meaning in the clause. So the right version should be:

10). B. I do not think all he has done is for money.

11). B. Mother does not believe that father has told the truth.

12). B. Tom did not think any employees have done their best.

\subsection{Time Expression}

In Chinese, the time is always put at the beginning of the sentence, and the order of the date should be year/ month/ day. In English, the time is always put at the end of the sentence, and the order of the date should be day/ month/ year or month/ day/ year. Although there are big differences between them, the testers have mastered them well. There are some sentences:

They are not seriously affected by mother tongue, so only $13.5 \%$ for NO.10 and $23.1 \%$ for NO.11 have translated them like the following:

13). A. This afternoon at 5:30 the club will hold a party to welcome the new member in 1428 .

14). A. My nephew was born on 1995 , September 12 th morning at half past two.

Also there is another difference between the time of Chinese and English, which is the expression of the lasting time. For instance: I have already received her letter for three weeks. In English 'receive' is an instant verb, so it cannot be used together with a period of time. $59.6 \%$ of the subjects have mistaken it with the negative influences of mother tongue. The right version should be: it has been three weeks since I received her letter.

\section{Ways to Prevent Negative Transfer}

\subsection{Suggestions for Teachers}

For China will hold 2008 Olympic Games, English learning now enjoys widespread appeal. The stress on translation highlights English teaching in universities. It has become the goal of English teaching, and good English teachers have to do the followings.

(1) Intrinsic motivation and the interest of the students

"The teacher must do everything which may let the students desire to invest effort in the learning for its own sake" (Penny, 280). If the students want to learn English well, and then all he has to do is to teach the students carefully and accurately.

(2) Understanding cross-linguistic differences between English and Chinese

The transfer errors appearing in the translation suggest that the learners are confused with the essential differences between those forms or structures that they conceive to be similar with the two languages. Moreover, results from investigation of learners' knowledge about cross-linguistic differences between English and Chinese have indicated that the subjects have difficulties between the two languages.

(3) Paying equal attention to cross-linguistic similarities and differences

Since it is very clear to us that cross-linguistic similarities can facilitate the study of TL, enough emphasis should be placed on the balanced explanation of the cross-linguistic similarities and differences. This method is not only feasible, but also practical. It is feasible because no matter how wide the gap between the two typologies of the native language and the target language is, cross-linguistic similarities are designed to appear and frequently used in the language study. If the language teachers analyze the cross-linguistic similarities of the two languages, they can strengthen the self-confidence and motivation of the language learners.

(4) Avoiding negative transfer

If the language teachers want the learners to avoid negative transfer, they should make the learners know the followings: A. Two different expressing system. B. Two different language families. C. Strategies of avoiding negative transfer. D. Avoid negative transfer in vocabulary. E. Avoid negative transfer in grammar. F. Avoid negative transfer in usage. G. Avoid negative transfer in teaching text.

\subsection{Suggestions for Learners}

A learner want to improve your translation, he must train himself more, and try to know more about English. He should realize the importance of translation in your study and life, even in your future work. Do as the follows, and he will gain more. 
(1) Thinking in English

To think in English, learners should avoid relating everything to their native language by making the TL as a separate system. Learners should learn to express themselves first in English and then translate it into Chinese.

(2) Reading in English extensively

The more a student reads, the better he gains English knowledge about culture, religion, etc. Reading widely is one of the best ways to acquire native-like English. So after-class reading with various kinds of materials should be done.

\section{Conclusion}

It is assumed that the student who comes in contact with a foreign language will find some features quite easy and others quite difficult. Those elements that are similar to his native language will be simple for him, and those elements that are different will be difficult. The teacher who has made a comparison of the foreign language with native language of the students will know better about what the real learning problems are and can better provide for teaching them. The learner should get rid of Chinese ways of thinking and try to combine the form with the meaning and the mode of expression in English. One task of teaching is to prevent such kind of interference caused by mother tongue.

\section{References}

Aronoff, Mark \& Janie Rees Miller. Ed. (2001). The Handbook of linguistics. Beijing: Foreign Language Teaching and Research Press.

Gass, Susan M \& Schachter Jacquelyn. Ed. (2006). Linguistic Perspectives on Second Language Acquisition. Beijing: World Publishing Company.

Gass. (1984). A Review of Interlanguage Syntac: Language Transfer and Language Universals. Language learning.

Jiang, Zukang. (2000). The Study of Second Language Acquisition. Shanghai: Shanghai Foreign Languages Education Press0.

Jin, Pengsun \& You Baona. (2005). The Influence of the First Language Negative Transfer on the Subject and the E-C Translation Techniques. Journal of North China Electric Power University, June.

Lado, R. (1957). Linguistics across Cultures. Ann Arbor: University of Michigan Press.

Li, C \& SA. Thompson. (1976). Subject and Topic. NewYork: Academic Press.

Odlin, T. (1989). Language Transfer. Cambridge: Cambridge University Press.

---, ed. (2001). Language Transfer: Cross-Linguistic Influence in Language Learning. Shanghai: Shanghai Foreign Languages Education Press.

Penny, Ur. Ed. (1996). A Course in Language Teaching: Practice and Theory. Cambridge: Cambridge University Press. Qiao, Ping. (2007). The Influence of Negative Transfer on Mother Tongue on the Unnecessary Words of C-E translation in English Teaching. Journal of Chengdu University (Education Sciences Edition), Vol. 21, No. 6.

Rod, Ellis. Ed. (1994). The Study of Second Language Acquisition. London: Oxford University Press.

---, ed. (2000). Second Language Acquisition. Shanghai: Shanghai Foreign Language Education Press.

Rutherford, W. Ed. (1984). Language Universals and Second Language Acquisition. John Benjamins Amsterdam.

Schachter, J. (1974). An Error in Error Analysis. Language Learning, 24: 205-14.

Stuart, C. Poole. Ed. (2000). An Introduction to Linguistics. Beijing: Foreign Languages Teaching and Research Press. 
Table 2.1 Ratio Made by Subjects in Pilot and Formal Study

\begin{tabular}{|c|c|c|c|c|c|}
\hline \multicolumn{3}{|l|}{ Pilot study (\%) } & \multicolumn{3}{|l|}{ Formal study (\%) } \\
\hline \multirow{3}{*}{ Subject omission } & 1 & 0 & \multirow{3}{*}{ Run-on sentences } & 1 & 30.8 \\
\hline & 2 & 7 & & 2 & 51.9 \\
\hline & 3 & 0 & & 3 & 11.5 \\
\hline \multirow{3}{*}{$\begin{array}{l}\text { The choice } \\
\text { pronoun-subject } \\
\text { nonporous subject }\end{array}$} & 4 & 100 & \multirow{3}{*}{$\begin{array}{lr}\text { The choice } & \text { of } \\
\text { pronoun-subject } & \text { and } \\
\text { nonporous subject }\end{array}$} & 4 & 100 \\
\hline & 5 & 100 & & 5 & 100 \\
\hline & 6 & 71 & & 6 & 100 \\
\hline \multirow{3}{*}{ Redundancy } & 7 & 35.7 & \multirow{3}{*}{ Redundancy } & 7 & 51.9 \\
\hline & 8 & 71 & & 8 & 82.7 \\
\hline & 9 & 71 & & 9 & 65.4 \\
\hline \multirow{3}{*}{ Time expression } & 10 & 21.4 & \multirow{3}{*}{ Time expression } & 10 & 13.5 \\
\hline & 11 & 21.4 & & 11 & 23.1 \\
\hline & 12 & 7 & & 12 & 59.6 \\
\hline \multirow{3}{*}{$\begin{array}{l}\text { The location of negative } \\
\text { object }\end{array}$} & 13 & 71 & \multirow{3}{*}{$\begin{array}{l}\text { The location of negative } \\
\text { object }\end{array}$} & 13 & 82.7 \\
\hline & 14 & 57.1 & & 14 & 71.2 \\
\hline & 15 & 78.6 & & 15 & 96.2 \\
\hline
\end{tabular}

